\title{
Recolonizing wolves influence the realized niche of resident cougars
}

\author{
L Mark Elbroch ${ }^{*}$, Patrick E Lendrum ${ }^{1}$, Jesse Newby², Howard Quigley ${ }^{1}$ and Daniel J Thompson ${ }^{3}$
}

\begin{abstract}
Background: Niche differentiation may betray current, ongoing competition between two sympatric species or reflect evolutionary responses to historic competition that drove species apart. The best opportunity to test whether ongoing competition contributes to niche differentiation is to test for behavioral shifts by the subordinate competitor in controlled experiments in which the abundance of the dominant competitor is manipulated. Because these circumstances are difficult to coordinate in natural settings for wide-ranging species, researchers seize opportunities presented by species reintroductions. We tested for new competition between reintroduced wolves and resident cougars in the Southern Yellowstone Ecosystem to assess whether wolves might be impacting the realized niche of sympatric cougars.

Results: Between 2002 and 2012, a period during which wolves increased from 15 to as high as 91 in the study area, cougars significantly increased the percentage of deer and decreased the percentage of elk in their diet in summer. Our top models explaining these changes identified elk availability, defined as the number of elk per wolf each year, as the strongest predictor of changing cougar prey selection. Both elk and deer were simultaneously declining in the system, though deer more quickly than elk, and wolf numbers increased exponentially during the same time frame. Therefore, we concluded that prey availability did not explain prey switching and that competition with wolves at least partially explained cougar prey switching from elk to deer. We also recorded 5 marked cougar kittens killed by wolves and 2 more that were killed by an undetermined predator. In addition, between 2005 and 2012, 9 adult cougars and 10 cougar kittens died of starvation, which may also be in part explained by competition with wolves.

Conclusions: Direct interspecific predation and shifting cougar prey selection as wolves increased in the system provided evidence for competition between recolonizing wolves and resident cougars. Through competition, recolonizing wolves have impacted the realized niche of resident cougars in the Southern Yellowstone Ecosystem (SYE), and current resident cougars may now exhibit a realized niche more reflective of an era when these species were previously sympatric in the Yellowstone Ecosystem.
\end{abstract}

Keywords: Canis lupus; Competition; Prey switching; Puma concolor; Realized niche; Wyoming; Yellowstone

\section{Background}

Resource competition describes a diverse suite of intraand interspecific interactions that shape ecological communities (Birch 1957; Schoener 1983; Petren and Case 1996). One way in which competition structures communities is through its influence on species ecological niches. The larger fundamental niche describes the ecological conditions in which a species may thrive on its own, whereas the smaller realized niche describes the ecological conditions in which the same species can

\footnotetext{
* Correspondence: melbroch@panthera.org

'Panthera, 8 West 40th Street, 18th Floor, New York, NY 10018, USA

Full list of author information is available at the end of the article
}

survive while under the additional constraints imposed by predators and competitors (Hutchinson 1957). Competition, therefore, drives evolutionary niche differentiation within and among species, as well as shapes the realized niches of sympatric species in ecological communities.

Consider wolves (Canis lupus) and cougars (Puma concolor). Wolves are the dominant competitors in most physical competition over shared resources (Ruth and Murphy 2010a). Wolves are coursing, social predators that select disadvantaged prey in areas of limited structural complexity where they can test their prey's condition (Husseman et al. 2003; Peterson et al. 2003). Cougars are solitary stalk-and-pounce predators that select prey

\section{要}


opportunistically (i.e., of any health) in areas where structural complexity (e.g., slope, trees, boulders) provide them an advantage (Husseman et al. 2003; Atwood et al. 2007; Ruth and Murphy 2010b). Thus, we expect wolves and cougars to inhabit and utilize different ecological niches, allowing them to spatially and temporally coexist (Husseman et al. 2003; Atwood et al. 2007); however, in the absence of wolves, cougars utilize areas traditionally assumed to be the dominion of coursing predators (Riley et al. 2004; Elbroch and Wittmer 2012). This suggests that where wolves are sympatric with cougars, wolves may impact the realized niche of cougars and that ongoing competition between the two species plays a role in structuring ecological systems.

Our best opportunity to test whether ongoing competition contributes to niche differentiation between species is to test for behavioral shifts by the subordinate competitor in controlled experiments in which the abundance of the dominant competitor is manipulated (Connell 1983). Could we, for example, detect prey switching or changes in habitat use by cougars as we increase or decrease the number of wolves in a controlled system? It is, however, logistically and perhaps ethically difficult to manipulate large carnivore abundances in natural systems. Instead, researchers must be quick to seize rare opportunities presented by species perturbations (e.g., reintroductions or removals) to test whether there is a change in the realized niche of the subordinate competitor (Kortello et al. 2007; Seddon et al. 2007).

The introduction of wolves in Northern Yellowstone National Park and central Idaho, USA, beginning in 1995, where wolves have been absent since 1926 (Haines 1996), provided such an opportunity. Here we provide a brief summary of research findings on competition between the two species to date: Kunkel et al. (1999) did not detect separation in prey selection or habit use in newly sympatric wolves and cougars in Montana and did not detect any form of competition in their formal analyses. They did, however, report kleptoparasitism of cougar kills by wolves and interspecific killing of cougars by wolves as evidence of interference competition. Ruth (2004b) and Kortello et al. (2007) reported increased cougar starvation as wolves increased in two different systems, and both studies attributed the change largely to interference competition with wolves and declining prey. Kortello et al. (2007) also detected cougar prey switching from elk to deer as wolf numbers increased (and elk numbers decreased) in Banff National Park, Alberta, as well as spatial avoidance between the two species at fine scales; they attributed these changes to exploitation competition because they believed wolves were diminishing elk numbers to levels where cougars needed to prey switch to survive. Kortello et al. also reported the intraspecific killing of one cougar by wolves as evidence of interference competition. Atwood et al. (2007) reported that cougars increased predation on elk (Cervus elaphus) and reduced predation on mule deer (Odocoileus hemionus) with the recolonization of wolves in southwest Montana; in contrast to Kortello et al. (2007), they attributed the change to elk switching habitats from open grasslands that mitigate predation risk from cougars to more structured habitats that mitigate predation risk from wolves, suggesting facilitation rather than any form of competition between top predators. Ruth et al. $(2011,2015)$ found that cougars increased their use of structurally complex habitats after the reintroduction of wolves in Northern Yellowstone National Park, implying a reduction in the spatial attributes of the cougar's realized niche. Further, wolves killed three adult cougars and five kittens in Northern Yellowstone over the course of their study (Ruth 2004a, 2015). Bartnick et al. (2013) found the probability of finding mule deer relative to elk at cougar kill sites increased during summer months in the Southern Yellowstone Ecosystem (SYE). The authors attributed the increased probability of detecting a mule deer as evidence of prey switching and interference competition, rather than exploitation competition as reported in Kortello et al. (2007). Bartnick et al. also reported an increase in the number of wolf tracks at cougar kills over time. Finally, Lendrum et al. (2014) observed that cougars in the SYE selected home ranges with higher "hunting opportunity" but further from wolves than expected, suggesting spatial displacement of cougars by wolves in high prey areas and current competition between the two species. When considered together, the results of these research projects strongly suggest some form of ongoing competition is contributing to niche separation between currently sympatric wolves and cougars.

In this study, we tested for changes in prey selection exhibited by a resident cougar population during wolf recolonization of the SYE as further evidence of ongoing competition between the two species. The SYE is a large undeveloped landscape where ungulate prey exhibit seasonal migrations (Sawyer et al. 2005; Smith 2007; Nelson et al. 2012; Elbroch et al. 2013) and winter snows force wolves, cougars, and their prey to share lower elevations in late winter (Kortello et al. 2007; Ruth et al. 2011; Elbroch et al. 2013). Evidence for competition between the two species implies that ongoing competition with wolves limits the realized niche of cougars. Following Bartnick et al.'s (2013) hypothesis that cougars in the SYE are increasingly selecting deer instead of elk in the presence of wolves, we tested for changes in actual cougar prey selection between 2002 and 2012, a period during which wolves increased from 15 to as high as 91 in the system (a $600 \%$ increase). We hypothesized that we would detect a shift from elk to deer only in summer, because in winter deer migrate almost entirely out of the study system, thus limiting the opportunities for prey 
switching (Elbroch et al. 2013). We predicted cougar prey selection might switch from elk to deer because of increased encounter rates with deer related to preferential hunting, an increase in cougar use of more complex habitats where deer are more abundant (Kortello et al. 2007), or declining elk availability in the study area. In addition, we expected cougar predation on elk calves to decrease over the course of the study due to exploitation competition with wolves and other predators over a potentially limited resource (Griffin et al. 2011; Ruth et al. 2015).

We also hypothesized that we would detect interference competition between wolves and cougars, as evidenced by increased cougar kill rates (in animals killed per week) between 2005 and 2012, a period during which wolves increased from 16 to as high as 91 . We expected summer cougar kill rates to increase because of a shift from larger (elk) to smaller (mule deer) prey (Knopff et al. 2010). We expected winter cougar kill rates to increase because of greater wolf presence at cougar kills (Bartnick et al. 2013), forcing cougars to abandon their kills more quickly and therefore to hunt more frequently (sensu Elbroch and Wittmer 2013a). Finally, we summarized cause-specific cougar mortality data over the full course of the study. Documenting wolves killing cougars would be the strongest evidence for current interference competition between the two species (Kortello et al. 2007) and that wolves are limiting the size of the cougar's realized niche in the Southern Yellowstone Ecosystem.

\section{Methods}

\section{Study area}

Our study area encompassed approximately $2300 \mathrm{~km}^{2}$ of the SYE, inclusive of portions of Grand Teton National Park, the National Elk Refuge, and the Bridger-Teton National Forest north of the town of Jackson, Wyoming (Fig. 1). Elevations in the study area ranged from $1800 \mathrm{~m}$ in the valleys to $>3600 \mathrm{~m}$ in the mountains. Plant communities included cottonwood (Populus angustifolia) riparian zones interspersed with sagebrush (Artemisia spp.) uplands at lower elevations. At intermediate elevations, aspen (Populus tremuloides), Douglas fir (Pseudotsuga menziesii), and lodgepole pine (Pinus contorta) were the dominant species. Engelmann spruce (Picea engelmannii) and subalpine fir (Abies lasiocarpa) were the primary tree species at the higher elevations (Knight 1996). The area was characterized by short, cool summers and long winters with frequent snowstorms. Precipitation occurred mostly as snow, and maximum snow depths ranged from $100 \mathrm{~cm}$ at lower elevations to $>245 \mathrm{~cm}$ at intermediate and higher elevations $(2000+\mathrm{m})$.

The study area supported a diverse community of large mammals. Carnivores included wolves, black bears (Ursus americanus), grizzly bears (Ursus arctos), coyotes (Canis latrans), and red foxes (Vulpes vulpes). Ungulates

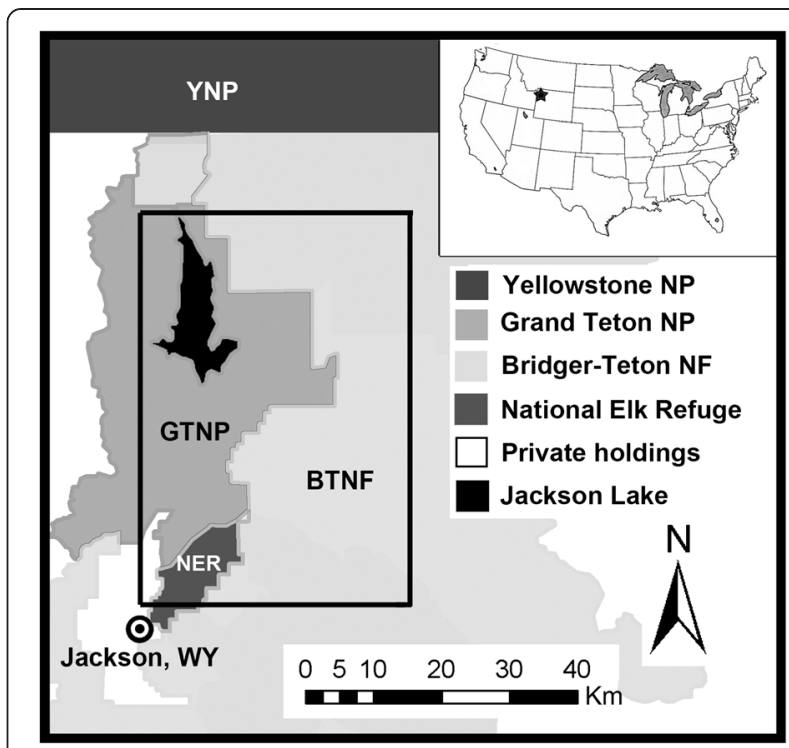

Fig. 1 Location of the study area in northwest Wyoming, USA, and a close-up of land ownership within the area of focus. The smaller rectangle delineated by a black line was the area in which we focused capture efforts and marked individual cougars

included elk, mule deer, moose (Alces alces), bison (Bison bison), pronghorn (Antilocapra americana), bighorn sheep (Ovis canadensis), and a small number of white-tailed deer (Odocoileus virginianus). Deer, elk, bighorn sheep, and pronghorn exhibited seasonal migrations (Sawyer et al. 2005; Smith 2007; Elbroch et al. 2013); elk were heavily harvested (10-12\% annually) in efforts to reduce their population, and deer and moose supported limited, male-only harvest rates. Bighorn sheep too supported a limited harvest of either sex (http://wgfd.wyo.gov/web2011/ HUNTING-1000184.aspx).

\section{Cougar capture and collar programming}

Beginning in 2001, we captured cougars during winters, from late November through March of the following year, when determining the presence of a cougar was facilitated by snow. We used trailing hounds to force cougars to retreat to a tree or rocky outcrop where we could safely approach them. Cougars were immobilized with ketamine $(4.0 \mathrm{mg} / \mathrm{kg})$ and medetomidine $(0.07 \mathrm{mg} /$ $\mathrm{kg}$ ), and then their temperature, heart rate, and respiration were monitored at 5-min intervals while they were processed, sampled, and fitted with either a VHF (Telonics, Mesa, AZ) or GPS collar (Telonics, Mesa, AZ; Televilt, Bandygatan, Sweden; Vectronics, Berlin, Germany). Once the animal was completely processed, the effects of the capture drugs were reversed with atipamezole $(0.375 \mathrm{mg} /$ $\mathrm{kg}$ ), and cougars departed the capture sites on their own. Our capture protocols for cougars followed those outlined in Quigley (2000), adhered to the guidelines outlined by the American Society of Mammalogists (Sikes 
et al. 2011), and were approved by the Jackson Institutional Animal Care and Use Committee (Protocol 02710EGDBS-060210).

\section{Documenting cause-specific mortalities}

Cougar collars were equipped with mortality sensors, which alerted researchers as to when the collars had not moved for prolonged periods $(8+\mathrm{h})$. We conducted investigations of sites where cougars died as soon as was possible and used signs of struggle or other animals to aid in determining the cause of death and whether species present at the site acted as predators or scavengers (Elbroch 2003). We also conducted field or lab gross necropsies, generally led by a veterinarian, to assess interior and exterior clues to determine cause-specific mortality. Blood and tissue samples were sent to the Wyoming State Veterinary Laboratory for additional disease analyses.

\section{Determining cougar prey selection and hunting habitats}

We conducted site searches of areas where triangulation of cougars wearing VHF collars revealed that they had not moved for $24+\mathrm{h}$, or spatially aggregated GPS points, called GPS clusters (Anderson and Lindzey 2003), indicated a cougar had remained in place for $8+h$. Prey remains, including hair, skin, rumen (stomach), and bone fragments, were used to identify prey species, and the state of prey remains, including the location of bite marks and feeding patterns, were used to determine whether the cougar had killed the animal or was scavenging. We determined the age of the prey by examining tooth eruption and wear patterns (Heffelfinger 2010) and separated prey into four age categories: calves and fawns $<1$ year old, yearlings $1-2$ years, subadults 2-3 years, and adults $3+$ years. Additionally, we recorded the general habitat type at the kill site: forest, edge, meadow, riparian, or rocky/barren. We later condensed habitat type into two categories: (1) forested, which included forest and edge, or (2) open habitat, which encompassed all remaining habitat types. To determine if cougars were hunting in forests more often over time, we employed a generalized linear model to assess changes in the percentage (\%) of kills found in forests in summer and winter from 2002 to 2012. $p$ values for generalized linear models were created based on asymptotic chisquare distributions (JMP 11, SAS Institute Inc., Cary, NC, USA).

\section{Defining the seasons and testing for differences in cougar prey selection}

Following well-established elk migration dates in the study area, we defined winter as December 1 of one year through May 31 of the next year, and summer as June 1 through November 30 of the same year (Elbroch et al. 2013). We examined seasonal prey selection from 2002 to 2012; however, because of limited sample sizes, we did not include 2002 or 2005 in the analysis of summer prey selection or 2003 in the analysis of winter prey selection.

To account for variable number of prey killed by individual cougars, we quantified each individual cougar's prey selection as the proportions of prey killed by each cougar, before conducting any population level analyses. We excluded non-ungulate prey for our analyses and divided the remainder into proportions of elk, deer, and "other ungulates," which included bighorn sheep, moose, and pronghorn (Fig. 2). Our analyses focused on the proportions of elk and mule deer killed by cougars because these two species composed $>80 \%$ of cougar diets in the study population (Elbroch et al. 2012). We employed generalized linear models to test whether the proportions of elk killed by cougars changed over time

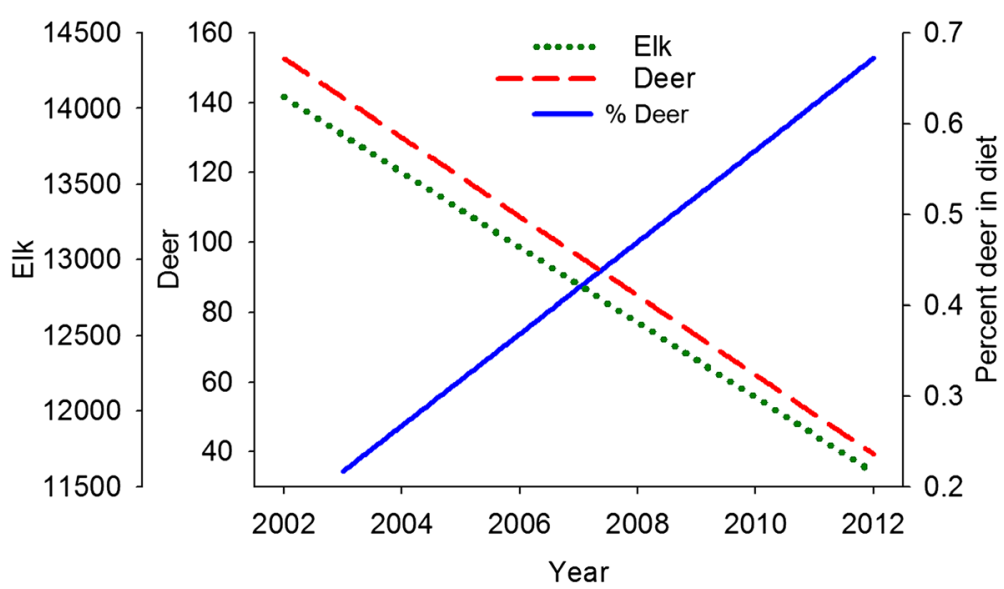

Fig. 2 Contrasting regression lines representing declining numbers of elk and deer, and the increasing proportions of deer in cougar summer diets over time 
in summers and winters. We then repeated these analyses to test whether the proportion of deer killed by cougars in each season changed over time. Last, we tested whether the proportion of elk calves killed in both seasons changed over time. When we detected a change, we conducted a multiple regression analysis (GLM) to determine if variation in prey selection could be explained by prey availability, winter severity, the number of wolves in the system, or a combination of these parameters (JMP, SAS Institute Inc., Cary, NC, USA). We employed annual Wyoming Game and Fish Department elk counts and cow-calf ratios conducted via helicopter transects across our study area and modeled in POP II stochastic modeling software (Lubow and Smith 2004; Fossil Creek Software, Fort Collins, CO, USA) as an index for the local elk population (WGFD Job Completion Reports, http://wgfd.wyo.gov/web2011/wildlife-1000496.aspx), and annual Wyoming Game and Fish Department mule deer counts conducted during winter in the southern portion of our study area (Unit 150) as an index for the local deer population (WGFD Job Completion Reports, http://wgfd.wyo.gov/web2011/wildlife-1000496.aspx). We employed wolf numbers reported in annual wolf recovery reports for the study area (US Fish and Wildlife Service, Nez Perce Tribe, National Park Service, USDA Wildlife Services 2004, 2005, 2006, 2007, 2008, 2009, 2010, 2011, 2012).

For our actual analyses, we defined relative elk availability in terms of wolves (the number of elk per wolf) to account for the fact that wolves primarily eat elk in our study area (Stevenson et al. 2011), wolves are dominant over cougars, and competition over this resource should be most fierce (Ruth et al. 2015). We defined deer availability in terms of elk (the number of deer per elk) to emphasize the importance of changing prey ratios in determining prey availability (Garrott et al. 2007; Ruth et al. 2015). As a proxy for the potential influence of winter severity on predator and prey abundances, we used winter snow depths from November to April for each year (SNOTEL site, Gros Ventre Summit; Table 1); snow depths influence prey mobility and thus prey vulnerability and availability to predators in winter, as well as prey condition and vulnerability and availability in early summer (Parker et al. 1984). In our regression examining the proportion of elk calves killed over time, we included an additional variable, elk cow-calf ratios (number of calves per 100 cows, WGFD Job Completion Reports, http://wgfd.wyo.gov/web2011/wildlife-1000496.aspx). All generalized linear models were conducted with a Poisson distribution with a logit function identity.

Prior to analysis, we used pairwise coefficient correlations, and a correlation cutoff of 0.6 , to test for significant correlation between independent variables. Wolf and elk numbers were highly correlated with elk availability, and deer and elk numbers were highly correlated with deer availability $(r>|0.80|)$; thus, raw wolf and prey numbers were removed from the analyses. We then ran all possible combinations of the variables and calculated Akaike's information criterion adjusted for small sample size $\left(\mathrm{AIC}_{c}, \Delta \mathrm{AIC}_{c}\right.$, and Akaike weight $w_{i}$; Burnham and Anderson 2002) to assess model performance and determine variables that influenced prey selection from 2002 to 2012 (7 models for changing elk and deer selection, and 15 for changing elk). Models that had $\geq 2 \Delta \mathrm{AIC}_{c}$ were considered to have predictive power of significant difference from the next model (Burnham and Anderson 2002). In cases in which multiple top models were identified, we used model averaging to determine individual parameter weights to compare their relative influence on predictor variables (Burnham and Anderson 2002).

Table 1 Annual estimates of wolves reported by USFW, elk availability (elk per wolf), deer availability (deer per elk), cow elk to calf ratios, and mean snow depth in the Southern Yellowstone Ecosystem, WY, USA, followed by the percentage of elk and deer that constituted cougar diets, the percentage of the total elk killed that were calves, and the percentage of kill sites found in forested habitat for summer seasons

\begin{tabular}{llllllllll}
\hline Year & Wolves & Elk/wolf & Deer/elk & Cow:calf & Snow depth $(\mathrm{cm})$ & \% elk & \% deer & \% calves & \% forest \\
\hline 2002 & 15 & 997.07 & 0.012 & 20 & 72.29 & $\mathrm{n} / \mathrm{a}$ & $\mathrm{n} / \mathrm{a}$ & $\mathrm{n} / \mathrm{a}$ & $\mathrm{n} / \mathrm{a}$ \\
2003 & 19 & 708.26 & 0.014 & 28 & 67.87 & 66.7 & 13.3 & 42 & 60 \\
2004 & 15 & 915.33 & 0.006 & 26 & 77.51 & 63 & 18.8 & 60 & 78.1 \\
2005 & 36 & 350.28 & 0.008 & 22 & 82.7 & $\mathrm{n} / \mathrm{a}$ & $\mathrm{n} / \mathrm{a}$ & $\mathrm{n} / \mathrm{a}$ & $\mathrm{n} / \mathrm{a}$ \\
2006 & 30 & 428.50 & 0.007 & 25 & 69.68 & 26.3 & 68.8 & 40 & 68.6 \\
2007 & 58 & 220.29 & 0.008 & 25 & 89.57 & 68.1 & 28.6 & 50 & 70 \\
2008 & 81 & 155.33 & 0.004 & 27 & 78.22 & 9.9 & 63.4 & 60 & 82.2 \\
2009 & 74 & 169.59 & 0.002 & 20 & 56.61 & 53.3 & 33.3 & 64 & 83.3 \\
2010 & 91 & 128.47 & 0.010 & 21 & 92.93 & 16.3 & 63.8 & 50 & \\
2011 & 85 & 140.92 & 0.008 & 17 & 54.9 & 27.7 & 52.8 & 100 & 95.4 \\
2012 & 83 & 144.36 & 0.002 & 25 & 60.11 & 69.8 & 83 & 76.4 \\
\hline
\end{tabular}




\section{Estimating kill rates and testing for increasing kill rates between 2005 and 2012}

We estimated seasonal kill rates in animals killed per week for cougars wearing GPS collars between 2005 and 2012, when we had sufficient samples of cougars wearing GPS collars to conduct the research. We employed models that differentiated between GPS clusters with a high probability of being a kill versus GPS clusters with a low probability of being a kill. GPS collars were programmed to acquire location data at variable rates, ranging from 3- to 10-h intervals, with the majority of collars being programmed to acquire six to eight locations each day. To identify clusters, GPS data were analyzed with a Python script (Python Software Foundation Hampton, NH) developed by Knopff et al. (2009) to identify two or more locations within $100 \mathrm{~m}$ and $\leq 48 \mathrm{~h}$ of each other. We did not include cougars wearing VHF collars in our kill rate calculations.

First, we developed competing models to test four spatial and seven temporal attributes of clusters potentially predictive of kill sites (Table 1; Anderson and Lindzey 2003; Ruth et al. 2010; Miller et al. 2013). We tested these models against our database of a subset of GPS clusters we visited in the field, and for which we determined whether or not a kill was present. Additional sites where the presence of a kill could be confirmed were provided by visits based on VHF radio telemetry for clusters later identified with GPS data stored on collars. For cluster analysis, site searches conducted $\geq 4$ months from the beginning date of cluster formation and site searches of questionable reliability (e.g., when snow fall may have obscured evidence) were omitted.

We employed logistic regression to assess the ability of univariate and multivariate models to predict at which clusters we would likely find a cougar kill. We employed residual plots of univariate models to assess assumptions of linearity and normality and transformed data accordingly. We also excluded models in which variables exhibited collinearity $\geq 0.6$. We applied backwards and forwards model selection to select the best supported model, based on Akaike's information criterion, and obtain parameter estimates. We did not use weighted parameter estimates for predictor variables because of the large number of highly correlated variables among models. We assessed the fit of the top model from receiver operative characteristic (ROC) curves (Hosmer and Lemshow 2000).

We employed sensitivity and specificity curves to assess the efficiency of models in predicting kill sites and determining the optimum probability cut-point for clusters to identify kills (Hosmer and Lemshow 2000). High sensitivity may effectively classify clusters with kills successfully (reduce false negatives) but is likely to attribute kills to clusters without them (increase false positives).
In contrast, high specificity may result in more false negatives but few false positives.

We applied our final model to GPS cluster data for all individuals that wore GPS collars to predict which clusters were likely to contain kills as follows:

$$
\begin{aligned}
\operatorname{Pr}(\text { kill })= & \exp ^{\left(\beta_{0}+\beta_{1} * X_{1}+\beta_{2} * X_{2}+\beta_{n} * X_{n}\right)} / 1 \\
& +\exp ^{\left(\beta_{0}+\beta_{1} * X_{1}+\beta_{2} * X_{2}+\beta_{n} * X_{n}\right)}
\end{aligned}
$$

where $\beta_{0}$ is the intercept and $\beta_{\mathrm{n}}$ are coefficients for predictor variables $X_{\mathrm{n}}$ (Manly et al. 1993). We applied this model to identify clusters that likely contained kills in the entire GPS location data from all cats. We used these identified clusters in the full GPS dataset to estimate seasonal kill rates for each individual cougar. We conducted a test of whether there were differences in kill rates due to season or cougar sex with a two-way analysis of variance, where individual cougar was included as a random effect.

Due to the final model's low success rate in classifying clusters, we examined an alternative model for identifying kills. This model was based on previous research by Anderson and Lindzey (2003) and Ruth et al. (2010), which employed the number of nights a cougar visited a cluster as an efficient means to distinguish between kill and non-kill sites. In this approach, kills were assigned only to clusters that spanned more than one night. We reported kill rates determined using both the "best" and night $>1$ models, because the benefit of the night $>1$ model's ability to positively detect kills at sites may have outweighed the cost of over-attributing kills to clusters where none were found. As this method likely missed small prey that could be consumed in shorter time frames, we defined these kill rates as ungulate-only kill rates. Then, we tested for changes in kill rate over time using linear regression, in which we included individual cougar as a random effect.

\section{Results}

\section{Cougar mortalities}

We determined cause-specific mortality of 33 cougar kittens and 45 subadults and adults from 2002 to 2012. In order from greatest frequency to least, 10 cougar kittens died of starvation (38\%), 5 kittens were killed by wolves (19\%), 5 kittens died of unknown causes (19\%), 2 kittens died from an unidentified predator (8\%), 2 kittens were killed by other cougars ( $8 \%), 1$ kitten died from disease ( $4 \%$ ), and 1 was killed by wildlife managers (4\%). In order from greatest frequency to least, 16 subadult and adult cougars were legally harvested (36\%), 9 died from starvation (20\%), 5 were killed by other cougars (11\%), 5 died of disease (11\%), 5 died of undetermined cause (11\%), 3 were killed by wildlife managers (7\%), 1 was illegally killed ( $2 \%$ ), and 1 died of old age 
(2\%). All kitten and adult starvations occurred after 2005, and there were zero cougars harvested from 2007 to 2012 .

\section{Seasonal prey selection and hunting habitats}

Between January 2002 and October 1, 2012, we recorded 411 winter prey and 239 summer prey killed by $28 \mathrm{fe}-$ male and 10 male cougars, and an additional 37 prey items recorded for unmarked cougars (30 winter, 7 summer). Of these, only 29 prey were not ungulates. Deer composed $42.4 \%$ of summer cougar diets but only $7.2 \%$ of winter diets. Elk composed $38.3 \%$ of summer cougar diets and $74.4 \%$ of winter diets.

We detected different changes in the proportion of elk and deer killed by cougars in summer between 2002 and 2012. We detected a positive change in proportions of deer $\left(\chi_{1,7}^{2}=5.89, p=0.01\right.$; Fig. 2$)$ and a negative change in proportions of elk $\left(\chi_{1,7}^{2}=4.47, p=0.03\right.$; Fig. 2$)$ killed during the summer season. The top model explaining changing cougar prey selection of deer included only elk availability $(\beta=-0.003$; Table 2$)$. In the case of cougar prey selection of elk, our analyses identified four top models (Table 3). Model averaging of top models identified elk availability $(\beta=-0.003)$ as the predictive variable of greatest weight $(w=1)$, then deer availability $(\beta=-20.960$; $w=0.49)$, and then snow $(\beta=-0.013 ; w=0.18)$ (Table 1). In contrast, we did not detect a change in prey selection by cougars for either elk $\left(\chi_{1,8}^{2}=0.28, p=0.60\right)$ or deer $\left(\chi_{1,8}^{2}=\right.$ $0.29, p=0.59$ ) during the winter season.

There was no change in the percentage of elk calves in cougar diets during winter seasons $\left(\chi_{1,7}^{2}=2.63, p=0.10\right)$; however, there was a significant increase in the percentage of calves killed during the summer season $\left(\chi_{1,7}^{2}=\right.$ 6.13, $p=0.01$ ). The results of our model comparisons identified three top models (within $2 \Delta$ AIC; Table 4). Model averaging identified cow-calf ratios $(\beta=0.240 ; w=$ $0.58)$ as the strongest predictor of changing cougar selection for elk calves, followed by snow $(\beta=-0.050 ; w=$ $0.45)$, then deer availability $(\beta=-137.345 ; w=0.29)$, and elk availability $(\beta=-0.001 ; w=0.16)$ (Table 1$)$.
The percentage of kills found in forested habitats did not change over time in winter $\left(\chi_{1,9}^{2}=0.60, p=0.44\right)$. During the summer season, however, there was a significant increase in the percentage of kills in forested habitats over the course of the study $\left(\chi_{1,7}^{2}=4.35, p=0.03\right)$ (Table 1). Of all kills across years, $76 \pm 14 \%$ were found in forests in summer and $58 \pm 14 \%$ were found in forests in winter.

\section{Cougar kill rates}

GPS cluster model development. From 2005 to 2012, we collected location data adequate to identify 2729 clusters from 17 cougars wearing GPS collars. During this same time period, we visited 309 clusters from 14 individuals (average clusters visited/cat $=22$; range $1-81$ clusters $/$ cat) to search for prey remains. Sites were visited between 0 and 98 days after initial cluster formation (average $=8$ days). We found kills at 269 clusters and classified 40 clusters as non-kills, and with these data, we tested our kill rate models.

The final logistic regression model for determining if a cluster was likely a kill included the cluster spanning more than one night $(z=3.042 ; p=0.002)$, the square root of the number of hours at night in cluster $(z=$ $2.084 ; p=0.037)$, fidelity $(z=2.205 ; p=0.027)$, and distance to nearest consecutive cluster $(z=2.284 ; p=$ 0.022 ). The probability of finding a kill was positively associated with all four variables included in the final model. Model fit was moderate for the final model $(\mathrm{AUC}=0.827)$. The probability cutoff of 0.887 maximized both sensitivity and selectivity in discriminating between clusters with and without kills; however, this cutoff resulted in only a $49.7 \%$ success of correctly classifying our known kill and non-kill clusters, identified with field investigations.

The variable "night $>1$ " was found to be the strongest predictor of a cluster being a kill in both the multivariate models and among all univariate models $\left(R^{2}\right.$ for night $>$ $1=0.148$; all other independent variables $R^{2}<0.057$ ). The night $>1$ model was found to successfully identify clusters as having kills $86 \%$ of instances but attributed

Table 2 Ranked models used to test explanatory variables (elk availability (elk/wolf), deer availability (deer/elk), and mean snow depth) for changes in proportions of deer in summer cougar diets over time, including AIC scores, $\triangle \mathrm{AIC}, W_{i}$, and likelihoods, in order of performance, best to worst

\begin{tabular}{lllllll}
\hline Model no. & No. of variables & Model & AlC & $\Delta$ AIC & $W_{i}$ & Likelihood \\
\hline 1 & 1 & $\{$ Elk/Wolf & 109.0864 & 0.00 & 0.82 & 1.00 \\
2 & 2 & $\{$ Deer/Elk+Elk/Wolf & 113.2963 & 4.21 & 0.10 & 0.12 \\
3 & 2 & $\{$ Elk/Wolf + Snow & 113.8864 & 4.80 & 0.07 & 0.09 \\
4 & 2 & $\{$ Deer/Elk+Elk/Wolf + Snow\} & 120.2914 & 11.21 & 0.00 & 0.00 \\
5 & 1 & $\{$ Deer/Elk\} & 139.6132 & 30.53 & 0.00 & 0.00 \\
6 & 2 & $\{$ Deer/Elk+Snow & 148.2827 & 39.20 & 0.00 & 0.00 \\
7 & 1 & $\{$ Snow & 153.6072 & 44.52 & 0.00 & 0.00 \\
\hline
\end{tabular}


Table 3 Ranked models used to test explanatory variables (elk availability (elk/wolf), deer availability (deer/elk), and mean snow depth) for changes in proportions of elk in summer cougar diets over time, including AIC scores, $\triangle$ AIC, $W_{i}$, and likelihoods, in order of performance, best to worst

\begin{tabular}{|c|c|c|c|c|c|c|}
\hline Model no. & No. of variables & Model & $\mathrm{AIC}$ & $\triangle \mathrm{AIC}$ & $W_{i}$ & Likelihood \\
\hline 1 & 1 & $\{$ Elk/Wolf $\}$ & 144.0788 & 0.00 & 0.33 & 1.00 \\
\hline 2 & 2 & $\{$ Deer/Elk + ElkMolf $\}$ & 144.1373 & 0.06 & 0.32 & 0.97 \\
\hline 3 & 2 & $\{$ Elk/Wolf + Snow $\}$ & 145.2729 & 1.19 & 0.18 & 0.55 \\
\hline 4 & 3 & $\{$ Deer/Elk + Elk/Wolf + Snow $\}$ & 145.4837 & 1.40 & 0.16 & 0.50 \\
\hline 5 & 2 & $\{$ Deer/Elk + Snow $\}$ & 165.3835 & 21.30 & 0.00 & 0.00 \\
\hline 6 & 1 & $\{$ Deer/Elk\} & 167.8292 & 23.75 & 0.00 & 0.00 \\
\hline 7 & 1 & $\{$ Snow $\}$ & 183.3962 & 39.32 & 0.00 & 0.00 \\
\hline
\end{tabular}

kills to $40 \%$ of sites at which we did not find prey remains. This resulted in a $46.0 \%$ classification success for the night $>1$ model. The benefit of the night $>1$ model's ability to positively detect kills at sites ( $86 \%$ for night $>$ 1 model vs. $75 \%$ for full model) may have outweighed the cost of over-attributing kills to clusters where none were found ( $40 \%$ for night $>1$ model vs. $25 \%$ for full model) (Table 4). Field crews often searched sites many days after the cluster had formed, and it was likely that they failed to find evidence of some kills that actually occurred. Given the potential bias in assigning non-kill clusters, it is reasonable to assume the model that overattributed kills to clusters was more reliable.

We did not detect a change in cougar kill rates in animals killed per week between 2005 and 2012 in summer $\left(F_{1,25.3}=0.090, p=0.767\right)$ or winter $\left(F_{1,31.1}=0.073, p=\right.$ $0.788)$. Mean summer and winter kill rates were not significantly different $(0.90 \pm 0.23$ animals/week and 0.99 \pm 0.22 animals/week, respectively).

\section{Discussion}

Determining whether one species influences the realized niche of another is difficult, if not impossible in natural systems (Schoener 1983). We seized a rare opportunity to test whether wolves are currently competing with and influencing the realized niche of sympatric cougars, following wolf reintroductions in Yellowstone National Park, USA. In Lendrum et al. (2014), we reported that cougars exhibited spatial displacement from wolves when selecting home ranges. In this paper, we tested whether cougars changed their prey selection and kill rates between 2002 and 2012, as further evidence of ongoing competition between the two species.

Table 4 Ranked models used to test explanatory variables (elk availability (elk/wolf), deer availability (deer/elk), cow elk to calf ratios, and mean snow depth) for changes in proportions of elk calves in summer cougar diets over time, including AIC scores, $\triangle \mathrm{AIC}, W_{i}$ and likelihoods, in order of performance, best to worst

\begin{tabular}{|c|c|c|c|c|c|c|}
\hline Model no. & No. of variables & Model & $\mathrm{AIC}$ & $\triangle \mathrm{AIC}$ & $W_{i}$ & Likelihood \\
\hline 1 & 2 & $\{$ Deer/Elk + Cow Calf $\}$ & 85.793 & 0.00 & 0.29 & 1.00 \\
\hline 2 & 2 & $\{$ Cow Calf + Snow $\}$ & 85.8264 & 0.03 & 0.29 & 0.98 \\
\hline 3 & 2 & $\{$ Elk/Wolf + Snow $\}$ & 87.0374 & 1.24 & 0.16 & 0.54 \\
\hline 4 & 1 & $\{$ Snow $\}$ & 88.254 & 2.46 & 0.09 & 0.29 \\
\hline 5 & 1 & $\{$ Cow Calf $\}$ & 88.8982 & 3.11 & 0.06 & 0.21 \\
\hline 6 & 3 & $\{$ Deer/Elk + Cow Calf + Snow $\}$ & 89.8507 & 4.06 & 0.04 & 0.13 \\
\hline 7 & 2 & $\{$ Deer/Elk + Snow $\}$ & 90.3895 & 4.60 & 0.03 & 0.10 \\
\hline 8 & 3 & $\{$ Elk/Wolf + Cow Calf + Snow $\}$ & 91.6315 & 5.84 & 0.02 & 0.05 \\
\hline 9 & 3 & $\{$ Deer/Elk + Elk/Wolf + Cow Calf $\}$ & 92.9873 & 7.19 & 0.01 & 0.03 \\
\hline 10 & 2 & $\{$ Elk/Wolf + Cow Calf $\}$ & 93.1075 & 7.31 & 0.01 & 0.03 \\
\hline 11 & 3 & $\{$ Deer/Elk + Elk/Wolf + Snow $\}$ & 93.6315 & 7.84 & 0.01 & 0.02 \\
\hline 12 & 1 & $\{$ Deer/Elk\} & 96.3017 & 10.51 & 0.00 & 0.01 \\
\hline 13 & 2 & $\{$ Deer/Elk + Elk/Wolf $\}$ & 97.3428 & 11.55 & 0.00 & 0.00 \\
\hline 14 & 1 & $\{$ Elk/Wolf $\}$ & 98.0101 & 12.22 & 0.00 & 0.00 \\
\hline 15 & 4 & $\{$ Deer/Elk + Elk/Wolf + Cow Calf + Snow $\}$ & 101.6466 & 15.85 & 0.00 & 0.00 \\
\hline
\end{tabular}


We found support for our first hypothesis that cougars would prey switch from elk to deer during summer as wolves increased in the system. Relative elk availability, defined as the number of elk per wolf, declined steeply over the course of the study. By 2012, elk availability was estimated to be $14 \%$ of what it was in 2002. Relative deer availability, defined by their abundance relative to elk abundance, also decreased over the course of the study. As both elk and deer availability decreased over the course of the study, changes in cougar prey selection were unlikely driven by changing elk or deer availability. Instead, our data strongly suggest that competition with increasing wolves in the system was the likely driver of changes in cougar prey selection over the last 12 years.

Exploitation competition is indirect competition through a shared resource, where the exploitation of the resource by the dominant competitor negatively impacts the fecundity and survival of the subordinate competitor (Petren and Case 1996). If cougars prey switched from elk to deer because elk numbers had declined to levels that could no longer sustain them, then this would be evidence of exploitation competition (e.g., Kortello et al. 2007). However, elk numbers only dropped from 14,956 to 11,982 over the course of the study and far exceed the capacity to maintain the low density of cougars for the study area (4.2 resident adults $/ 890 \mathrm{~km}^{2}$ in 2011 in Elbroch et al. 2012). Instead, our results better support an alternate explanation for how competition may be playing out between wolves and cougars in the SYE-one that suggests that changing cougar prey selection was driven by changing cougar habitat use. If cougars have shifted to more complex habitats to mitigate direct interference competition with coursing wolves, as has been shown in Northern Yellowstone (Ruth et al. 2011, 2015), then this shift in habitat use likely led to increased encounter rates with more forest-dependent mule deer. In support of this hypothesis, we did in fact detect an increase in the percentage of kill sites found in forested habitats in summers over the course of the study.

Contrary to our prediction that cougars would decrease their predation on elk calves during wolf and grizzly bear recolonization (Griffin et al. 2011), cougars increased their predation of elk calves in summers over the course of the study, even while wolves, too, preferentially selected for elk calves (Stevenson et al. 2011). In contrast, cougars in Northern Yellowstone increased the percentage of adult elk in their diet as cow-calf ratios decreased after wolf reintroductions (Ruth et al. 2015). The fact that cow-calf ratios in the SYE remained consistent as wolves increased in the system over the course of the study is likely reflective of high elk abundance and high elk fecundity and survivorship supported by supplemental feeding (Smith 2007). Therefore, the fact that cougars increased the number and proportion of calves in their diet while wolves increased in the system may indicate that elk calves in our study system have yet to drop in abundance enough to become a limited resource for subordinate cougars.

Also contrary to our hypothesis, we did not detect any changes in kill rates for either summer or winter, as we would expect as evidence of interference competition. This was likely due to our methods rather than the ecological reality of the system, and a more intensive field effort may have yielded different results (Knopff et al. 2010; Elbroch and Wittmer 2013b). Because we employed the night $>1$ model to quantify kill rates, we limited our ability to detect small prey or large prey when large competitors displaced cougars from their kills (Elbroch and Wittmer 2013a). This would influence both our comparison of selection for smaller ungulates and the predictive power of our kill rate models. The multiplicity of GPS fix rates employed over the life of the project also likely reduced the effectiveness of many explanatory variables in identifying clusters with and without kills. For these reasons, our methods may have failed to detect cougar prey switching to smaller prey that may have increased their kill rates.

We recorded 5 marked cougar kittens killed by wolves (23\% of known-cause mortalities) during the course of the study and 2 more that were killed by an undetermined predator which may or may not have been wolves. In addition, between 2005 and 2012, 9 adult cougars (20\% of known-cause mortalities) and 10 cougar kittens ( $45 \%$ of known-cause mortalities) died of starvation, which may also be in part explained by competition with wolves (Kunkel et al. 1999; Ruth 2004b; Ruth et al. 2015). Direct mortalities provide strong evidence for interference competition between recolonizing wolves and resident cougars in the Southern Yellowstone Ecosystem.

\section{Conclusions}

The spatial displacement of cougars by wolves in the SYE reported in Lendrum et al. 2014, in combination with changes in cougar prey selection and interspecific competitive killing of resident cougars by recolonizing wolves (because kittens were not entirely consumed by wolves; Lourenço et al. 2013) that we report here, provides strong evidence for newly established and now ongoing competition between these two species. During the last 12 years, resident cougars in the SYE may have served as naïve intermediaries relearning to coexist with a dominant competitor absent since 1926, when the last wolf was killed in Yellowstone National Park (Haines 1996). Through competition, recolonizing wolves have impacted the realized niche of resident cougars in the SYE, and current resident cougars may now exhibit a realized niche more reflective of an era when these species were previously sympatric in the Yellowstone Ecosystem. 


\section{Competing interests}

The authors declare that they have no competing interests.

\section{Authors' contributions}

$M E, J N$, and $H Q$ designed the study. $M E, J N, P L, H Q$, and DT participated in fieldwork. ME, PL, and JN ran the analyses and wrote the manuscript. $\mathrm{HQ}$ and DT provided additional data integral to the study. All coauthors contributed to the editing of the manuscript. All authors read and approved the final manuscript.

\section{Authors' information}

ME is a Science Director for Panthera and the principal investigator for Panthera's Teton Cougar Project (PTCP) in northwest Wyoming. PL was a biologist for PTCP and is now a graduate researcher at Colorado State University. JN was a biologist for PTCP and now works for Montana Fish, Wildlife, and Parks. HQ initiated PTCP and is now Executive Director of Jaguar and Puma Programs for Panthera. DT is the Wyoming Game and Fish Department liaison to PTCP and an active collaborator on research.

\section{Acknowledgements}

We thank our cooperators, including D. Craighead (Craighead Beringia South), K. Murphy (Bridger-Teton NF), S. Cain (Grand Teton NP), T. Fuchs (WY Game and Fish Dept), and E. Cole (National Elk Refuge); our supportive funders, the Summerlee Foundation, The Richard King Mellon Foundation, The Charles Engelhard Foundation, The Laura Moore Cunningham Foundation, Tim and Karen Hixon Foundation, National Geographic Society, The Norcross Wildlife Foundation, Inc., Earth Friends Conservation Fund, the Cougar Fund, The Bay Foundation, Michael Cline Foundation, Eugene V. \& Clare E. Thaw Charitable Trust, Connemara Fund, Hogan Films, National Fish and Wildlife Foundation, Community Foundation of Jackson Hole, The Oregon Zoo Foundation, Mr. and Mrs. G. Ordway, Mr. and Mrs. M. Manship, Mr. and Mrs. N. Jannotta, Mr. L. Westbrook, Mr. and Mrs. S. Robertson, Mr. R. Comegys; and several anonymous foundation and individual donors. Thanks also to T. Ruth for her generous review of our manuscript, which greatly enhanced its strength and clarity, and for the feedback of one more anonymous reviewer. No funders or funding organizations have any claim on the data collected as part of this research nor the products that were developed as part of this research, nor did any funders or funding organizations play a role in any decision-making in how the data was analyzed, presented, or published as part of this manuscript.

\section{Author details}

${ }^{1}$ Panthera, 8 West 40th Street, 18th Floor, New York, NY 10018, USA. ${ }^{2}$ Craighead Beringia South, PO Box 147, Kelly, WY 83011, USA. ${ }^{3}$ Wyoming Game and Fish, 260 Buena Vista, Lander, WY 82520, USA.

Received: 12 June 2014 Accepted: 6 May 2015

Published online: 14 May 2015

\section{References}

Anderson CR, Lindzey FG (2003) Estimating cougar predation rates from GPS location clusters. J Wildlife Manage 67:307-316

Atwood TC, Gese EM, Kunkel KE (2007) Comparative patterns of predation by cougars and recolonizing wolves in Montana's Madison Range. J Wildlife Manage 71:1098-1106

Bartnick TR, Van Deelen TR, Quigley HB, Craighead D (2013) Variation in cougar predation habits during wolf recovery in the southern Greater Yellowstone Ecosystem. Can J Zoolog 91:82-93

Birch LC (1957) The meanings of competition. Am Nat 91:5-18

Burnham KP, Anderson DR (2002) Model selection and multimodel inference: a practical information theoretic approach, 2nd edn. Springer, New York, USA

Connell JH (1983) On the prevalence and relative importance of interspecific competition: evidence from field experiments. Am Nat 122:661-696

Elbroch M (2003) Mammal track and signs: a guide to North American species. Stackpole Books, Mechanicsburg, USA

Elbroch M, Wittmer HU (2012) Puma spatial ecology of in open habitats with aggregate prey. Mamm Biol 77:377-384

Elbroch LM, Wittmer HU (2013a) Nuisance ecology: do scavenging condors exact foraging costs on pumas in Patagonia? PLoS One 8:e53595

Elbroch LM, Wittmer HU (2013b) The effects of puma prey selection and specialization on less abundant prey in Patagonia. J Mammal 94:259-268
Elbroch M, Quigley H, Craighead D (2012) Teton Cougar Project 2012 progress report. Craighead Beringia South, Kelly, WY, USA

Elbroch LM, Lendrum PE, Newby J, Quigley H, Craighead D (2013) Seasonal foraging ecology of non-migratory cougars in a system with migrating prey. PLoS One 8:e83375. doi:10.1371/journal.pone.0083375

Garrott RA, Bruggeman JE, Becker MS, Kalinowski ST, White PJ (2007) Evaluating prey switching in wolf-ungulate systems. Ecol Appl 17:1588-1597

Griffin KA, Hebblewhite M, Robinson HS, Zager P, Barber-Meyer SM, Christianson D, Creel S, Harris NC, Hurley MA, Jackson DH, Johnson BK, Myers WL, Raithel JD, Schlegel M, Smith BL, White C, White PJ (2011) Neonatal mortality of elk driven by climate, predator phenology and predator community composition. J Anim Ecol 80:1246-1257

Haines AL (1996) The Yellowstone story — a history of our first national park. University Press of Colorado, Niwot, CO, USA

Heffelfinger J (2010) Age criteria for Southwestern game animals. Special Report \#19. Arizona Game and Fish Department, USA

Hosmer DW, Lemshow S (2000) Applied logistic regression. John Wiley and Sons, New York, USA

Husseman JS, Murray DL, Power G, Mack C, Wenger CR, Quigley H (2003) Assessing differential prey selection patterns between two sympatric large carnivores. Oikos 101:591-601

Hutchinson GE (1957) Concluding remarks. Cold Spring Harb Symp Quant Biol 22:415-427

Knight DH (1996) Mountains and plains: the ecology of Wyoming landscapes. Yale University Press, CT, USA

Knopff KH, Knopff AA, Warren MB, Boyce MS (2009) Evaluating global positioning system telemetry techniques for estimating cougar predation parameters. J Wildlife Manage 73:586-597

Knopff KH, Knopff AA, Kortello A, Boyce MS (2010) Cougar kill rate and prey composition in a multiprey system. J Wildlife Manage 74:1435-1447

Kortello AD, Hurd TE, Murray DL (2007) Interactions between cougars (Puma concolor) and gray wolves (Canis lupus) in Banff National Park, Alberta. Ecoscience 14:214-222

Kunkel KE, Ruth TK, Pletscher DH, Hornocker MG (1999) Winter prey selection by wolves and cougars in and near Glacier National Park, Montana. J Wildlife Manage 63:901-910

Lendrum PE, Elbroch LM, Quigley $H$, Thompson DJ, Jimenez M, Craighead D (2014) Home range characteristics of a subordinate predator: selection for refugia or prey availability? J Zool doi:10.1111/jzo.12153

Lourenço R, Penteriani V, Rabaça JE, Korpimäki E (2013) Lethal interactions among vertebrate top predators: a review of concepts, assumptions and terminology. Biol Rev doi: 10.1111/brv.12054

Lubow BC, Smith BL (2004) Population dynamics of the Jackson elk herd. J Wildlife Manage 68:810-829

Manly B, McDonald L, Thomas D (1993) Resource selection by animals. Chapman \& Hall, New York, USA

Miller CS, Hebblewhite M, Miquelle DG, Seryodkin IV, Goodrich JM (2013) Estimating Amur tiger (Panthera tigris altaica) kill rates and consumption rates using GPS collars. J Mammal 94:845-855

Nelson AA, Kauffman MJ, Middleton AD, Jimenez M, McWhirter D, Barber J, Gerow K (2012) Elk migration patterns and human activity influence wolf habitat use in the Greater Yellowstone Ecosystem. Ecol Appl 22:2293-2307

Parker KL, Robbins CT, Hanley TA (1984) Energy expenditures for locomotion by mule deer and elk. J Wildl Manage 48:474-488

Peterson RO, Ciucci P, Mech LD, Boitani L (2003) The wolf as a carnivore. In: Wolves: behaviour, ecology and conservation. University of Chicago Press, Chicago, USA, pp 104-130

Petren K, Case TJ (1996) An experimental demonstration of exploitation competition in an ongoing invasion. Ecology 77:118-132

Quigley K (2000) Immobilization and biological sampling protocols. Hornocker Wildlife Institute/Wildlife Conservation Society, Bozeman, MT, USA

Riley SJ, Nesslage GM, Maurer BA (2004) Dynamics of early wolf and cougar eradication efforts in Montana: implications for conservation. Biol Conserv 119:575-579

Ruth TK (2004a) Ghost of the Rockies: the Yellowstone cougar project. Yellowstone Science 12:13-24

Ruth TK (2004b) Patterns of resource use among cougars and wolves in northwestern Montana and southeastern British Columbia. Dissertation, University of Idaho, Moscow, USA

Ruth TK, Murphy K (2010a) Competition with other carnivores for prey. In: Hornocker M, Negri S (eds) Cougar: ecology and conservation. University of Chicago Press, Chicago, USA, pp 163-172 
Ruth TK, Murphy K (2010b) Cougar-prey relationships. In: Hornocker M, Negri S (eds) Cougar: ecology and conservation. University of Chicago Press, Chicago, USA, pp 138-162

Ruth TK, Buotte PC, Quigley HB (2010) Comparing ground telemetry and Global Positioning System methods to determine cougar kill rates. J Wild Manage 74:1122-1133

Ruth TK, Haroldson MA, Murphy KM, Buotte PC, Hornocker MG, Quigley HB (2011) Cougar survival and source-sink structure on Greater Yellowstone's Northern Range. J Wildlife Manage 75:1381-1398

Ruth TK, Buotte PC, Hornocker MG (2015) Yellowstone cougars: ecology before and during wolf reestablishment. University Press of Colorado, Boulder, CO, USA, in press

Sawyer H, Lindzey F, McWhirter D (2005) Mule deer and pronghorn migration in western Wyoming. Wildlife Soc B 33:1266-1273

Schoener TW (1983) Field experiments on interspecific competition. Am Nat 122:240-285

Seddon PJ, Armstrong DP, Maloney RF (2007) Developing the science of reintroduction biology. Conserv Biol 21:303-312

Sikes RS, Gannon WL, the Animal Care and Use Committee of the American Society of Mammalogists (2011) Guidelines of the American Society of Mammalogists for the use of wild mammals in research. J Mammal 92:235-253

Smith BL (2007) Migratory behavior of hunted elk. Northwest Sci 81:251-264

Stevenson J, Jimenez M, Dewey S, Cain S (2011) Wildlife research: wolf predation. In: Cain SL (ed) Wildlife conservation, management, and research. 2011 National Park Service, Grand Teton National Park, Moose, WY, USA, pp 55-56

US Fish and Wildlife Service, Idaho Department of Fish and Game, Montana Fish, Wildlife and Parks, Nez Perce Tribe, National Park Service, Blackfeet Nation, Confederated Salish and Kootenai Tribes, Wind River Tribes, Washington Department of Fish and Wildlife, Oregon Department of Fish and Wildlife, Utah Department of Natural Resources, USDA Wildlife Services (2012) Northern Rocky Mountain Wolf Recovery Program 2011 Interagency Annual Report. USFWS, Helena, MT, USA

US Fish and Wildlife Service, Montana Fish, Wildlife and Parks, Nez Perce Tribe National Park Service, Blackfeet Nation, Confederated Salish and Kootenai Tribes, Wind River Tribes, Washington Department of Wildlife, Oregon Department of Wildlife, Utah Department of Natural Resources, USDA Wildlife Services (2011) Rocky Mountain Wolf Recovery 2010 Interagency Annual Report. USFWS, Helena, MT, USA

US Fish and Wildlife Service, Nez Perce Tribe, National Park Service, Montana Fish, Wildlife and Parks, Idaho Fish and Game \& USDA Wildlife Services (2005) Rocky Mountain Wolf Recovery 2004 Annual Report. USFWS, Helena, MT, USA

US Fish and Wildlife Service, Nez Perce Tribe, National Park Service, Montana Fish, Wildlife and Parks, Idaho Fish and Game, USDA Wildlife Services (2006) Rocky Mountain Wolf Recovery 2005 Annual Report. USFWS, Helena, MT, USA

US Fish and Wildlife Service, Nez Perce Tribe, National Park Service, Montana Fish, Wildlife and Parks, Idaho Fish and Game, USDA Wildlife Services (2007) Rocky Mountain Wolf Recovery 2006 Annual Report. USFWS, Helena, MT, USA

US Fish and Wildlife Service, Nez Perce Tribe, National Park Service, Montana Fish, Wildlife \& Parks, Blackfeet Nation, Confederated Salish and Kootenai Tribes, Idaho Fish and Game, USDA Wildlife Services (2008) Rocky Mountain Wolf Recovery 2007 Interagency Annual Report. USFWS, Helena, MT, USA

US Fish and Wildlife Service, Nez Perce Tribe, National Park Service, Montana Fish, Wildlife \& Parks, Blackfeet Nation, Confederated Salish and Kootenai Tribes, Idaho Fish and Game, USDA Wildlife Services (2009) Rocky Mountain Wolf Recovery 2008 Interagency Annual Report. USFWS, Helena, MT, USA

US Fish and Wildlife Service, Nez Perce Tribe, National Park Service, Montana Fish, Wildlife \& Parks, Blackfeet Nation, Confederated Salish and Kootenai Tribes, Idaho Fish and Game, USDA Wildlife Services (2010) Rocky Mountain Wolf Recovery 2009 Interagency Annual Report. USFWS, Helena, MT, USA

US Fish and Wildlife Service, Nez Perce Tribe, National Park Service, USDA Wildlife Services (2004) Rocky Mountain Wolf Recovery 2003 Annual Report. USFWS, Helena, MT, USA

\section{Submit your manuscript to a SpringerOpen ${ }^{\circ}$ journal and benefit from:}

- Convenient online submission

- Rigorous peer review

- Immediate publication on acceptance

- Open access: articles freely available online

- High visibility within the field

- Retaining the copyright to your article

Submit your next manuscript at $>$ springeropen.com 